\title{
Successful Intervention for Pressure Ulcer by Nutrition Support Team: A Case Report
}

\author{
Shigeki Inuia, b Yuko Konishi ${ }^{b, c}$ Yoko Yasuic \\ Toshiko Haradab Satoshi Itami ${ }^{\mathrm{a}}$ \\ ${ }^{a}$ Department of Regenerative Dermatology, Graduate School of Medicine, Osaka

 \\ University Hospital, Osaka, Japan
}

\section{Key Words}

Pressure ulcer $\cdot$ Heart failure $\cdot$ Anorexia $\cdot$ Nutrition support team

\begin{abstract}
A 23-year-old woman with heart failure developed pressure ulcer on her sacral area due to a long-term bed rest and impaired hemodynamics. The ulcer improved only slightly after 2 months with povidone-iodine sugar ointment because of severe nausea and anorexia. Then, the nutrition support team (NST) started intervention and estimated the patient's malnutrition from her body weight (30.1 kg), body mass index (BMI) (13.9), triceps skinfold thickness (TSF) $(3.5 \mathrm{~mm})$, arm circumference (AC) $(17.2 \mathrm{~cm})$ and serum albumin $(2.6 \mathrm{~g} / \mathrm{dl})$. The NST administrated an enteral nutrition formula through a nasogastric tube and tried to provide meals according to the patient's taste. Although DESIGN score improved to 7 (DESIGN: d2e1s $2 \mathrm{i} 1 \mathrm{~g} 1 \mathrm{n} 0=7$ ) 2 months later, severe nausea prevented the patient from taking any food perorally. However, after nasogastric decannulation, her appetite improved and 1 month later her body weight increased to $32.8 \mathrm{~kg}$, her BMI to 15.2, TSF to $7.5 \mathrm{~mm}, \mathrm{AC}$ to $19.7 \mathrm{~cm}$ and serum albumin to $4.1 \mathrm{~g} / \mathrm{dl}$, and the wound completely healed.
\end{abstract}

\section{Case Report}

A 23-year-old Japanese woman, using a cardiac assist device for heart failure caused by dilated cardiomyopathy, developed pressure ulcer on her sacral area due to a long-term bed rest and impaired hemodynamics (fig. 1). The DESIGN score [1] was D4e2s4i2G3n1 = 16. In spite of applying povidoneiodine sugar ointment, the ulcer only slightly improved for 2 months (DESIGN: D4e1s4i1G3n1 = 14) because severe nausea and anorexia reduced the patient's food intake to only about one fruit a day. Then, the intervention by nutrition support team (NST) started intervention and estimated her nutritional status. Her body weight was $30.1 \mathrm{~kg}$, body mass index (BMI) 13.9 (standard = 22; height = $147 \mathrm{~cm}$ ), triceps skinfold thickness (TSF) $3.5 \mathrm{~mm}$ (standard $=14.0 \mathrm{~mm}$ ), arm circumference (AC) 17.2 $\mathrm{cm}$ (standard $=24.6 \mathrm{~cm}$ ) and serum albumin $2.6 \mathrm{~g} / \mathrm{dl}$ (normal: $3.8 \sim 5.3 \mathrm{~g} / \mathrm{dl}$ ), demonstrating her severe 


\begin{tabular}{l|l|l|l} 
Case Reports $\boldsymbol{h}$ & Case Rep Dermatol 2010;2:120-124 & Published online: July 2, 2010 & $\begin{array}{l}\text { @ 2010 S. Karger AG, Basel } \\
\text { ISSN 1662-6567 } \\
\text { www.karger.com/cde }\end{array}$ \\
\hline
\end{tabular}

malnutrition. The administration of an enteral nutrition formula containing low residue was started through a nasogastric tube. Since the patient's basal energy expenditure, calculated by using the HarrisBenedict formula based on her putative standard weight $(47.5 \mathrm{~kg})$, was $1,283 \mathrm{kcal} / \mathrm{day}(27 \mathrm{kcal} / \mathrm{kg} / \mathrm{day})$, the total energy intake, including oral feeding, was decided to be $1,384 \mathrm{kcal} / \mathrm{day}$. Additionally, the NST tried to provide meals according to her taste. Although the DESIGN score improved to 7 (DESIGN: $\mathrm{d} 2 \mathrm{e} 1 \mathrm{~s} 2 \mathrm{i} 1 \mathrm{~g} 1 \mathrm{n} 0=7$ ) 2 months later, the severe nausea still prevented the patient from taking any foods perorally. Therefore, expecting an increase of her appetite, we decided nasogastric decannulation, which resulted in the disappearance of her nausea. Her peroral food intake, including food and enteral nutrition formula, became approximately $1,600 \mathrm{kcal} /$ day. Finally, 1 month later, her body weight increased to $32.8 \mathrm{~kg}$, her BMI to 15.2 , TSF to $7.5 \mathrm{~mm}, \mathrm{AC}$ to $19.7 \mathrm{~cm}$ and serum albumin to $4.1 \mathrm{~g} / \mathrm{dl}$, and subsequently the wound completely healed (fig. 2).

\section{Discussion}

Strategies taking various aspects into account, including body pressure dispersion, local wound control, nutrition management and systemic condition improvement, are necessary for preventing and treating pressure ulcers [2]. We have previously reported that the systemic condition is pivotal in the cure of pressure ulcers in cirrhosis, which healed after liver transplantation in two cases [3], and we also reported that local maceration control was significant in another case with recalcitrant pressure ulcer [4]. Although nutrition intervention seems indispensable to manage pressure ulcers, a systemic review concluded that it reduces the risk of developing pressure ulcers but its preferable effect on healing of pressure ulcers remains to be further confirmed [5]. However, Oka et al. [6] from Japan reported usefulness of nutrition intervention in a similar case of pressure ulcer complicated by malnutrition. Furthermore, the recent guidelines from the Japan Society of Pressure Ulcers recommend the administration of proper energy and protein for existing pressure ulcers as a recommendation level B [2]. Moreover, the more recent reference guide from the European Pressure Ulcer Advisory Panel and National Pressure Ulcer Advisory Panel [7] emphasizes the role of nutrition in pressure ulcer healing and estimates strength of evidence rating for recommendations about various nutritional interventions, such as nutritional assessment and regulation of calories, proteins, vitamins, minerals and hydration (table 1). In support of this, the intervention and evaluation by an NST was very helpful for the treatment of our case, also indicating the importance of collaboration and a common understanding of the patients' situation among medical staff, including the pressure ulcer advisory group and the NST. 


\begin{tabular}{c|l|l|l} 
Case Reports $\boldsymbol{h}$ & Case Rep Dermatol 2010;2:120-124 & Published online: July 2, 2010 & $\begin{array}{l}\odot 2010 \text { S. Karger AG, Basel } \\
\text { ISSN 1662-6567 } \\
\text { www.karger.com/cde }\end{array}$ \\
\hline
\end{tabular}

Table 1. Summary of recommendations concerning nutritional interventions according to 'Treatment of Pressure Ulcers: Quick Reference Guide' [7]

\author{
Strength of Evidence B \\ Calories \\ Provide sufficient calories \\ Provide enhanced foods and/or oral supplements between meals if needed \\ Proteins \\ Provide adequate protein for positive nitrogen balance for an individual with a pressure ulcer \\ Vitamins and minerals \\ Provide adequate vitamins and minerals \\ Encourage consumption of a balanced diet that includes good sources of vitamins and minerals \\ Offer vitamin and mineral supplements when dietary intake is poor or deficiencies are confirmed or \\ suspected
}

Strength of Evidence C

Assessment

Screen and assess nutritional status for each individual with a pressure ulcer at admission and with each condition change - and/or when progress toward pressure ulcer closure is not observed. Refer all individuals with a pressure ulcer to the dietitian for early assessment of and intervention for nutritional problems.

Assess weight status for each individual to determine weight history and significant weight loss from usual body weight ( $>5 \%$ change in 30 days or $>10 \%$ in 180 days).

Assess the individual's ability to eat independently.

Assess the adequacy of total nutrient intake (food, fluid, oral supplements, enteral/parenteral feedings).

\title{
Calories
}

Provide $30-35 \mathrm{kcal} / \mathrm{kg}$ body weight for individuals under stress with a pressure ulcer. Adjust formula based on weight loss, weight gain, or level of obesity. Individuals who are underweight or who have had significant unintentional weight loss may need additional kcal to cease weight loss and/or regain lost weight.

Revise and modify (liberalize) dietary restrictions when limitations result in decreased food and fluid intake.

These adjustments are to be managed by a dietitian or medical professional.

Consider nutritional support (enteral or parenteral nutrition) when oral intake is inadequate. This must be consistent with the individual's goals.

Proteins

Offer 1.25 to $1.5 \mathrm{~g}$ protein $/ \mathrm{kg}$ body weight daily for an individual with a pressure ulcer when compatible with goals of care, and reassess as condition changes.

Assess renal function to ensure that high levels of protein are appropriate for the individual.

Hydration

Provide and encourage adequate daily fluid intake for hydration.

Monitor individuals for signs and symptoms of dehydration: changes in weight, skin turgor, urine output, elevated serum sodium, or calculated serum osmolality.

Provide additional fluid for individuals with dehydration, elevated temperature, vomiting, profuse sweating, diarrhea, or heavily draining wounds.

Strength of Evidence A: the recommendation is supported by direct scientific evidence from properly designed and implemented controlled trials on pressure ulcers in humans (or humans at-risk for pressure ulcers), providing statistical results that consistently support the guideline statement; Strength of Evidence $B$ : the recommendation is supported by direct scientific evidence from properly designed and implemented clinical series on pressure ulcers in humans (or humans at-risk for pressure ulcers), providing statistical results that consistently support the recommendation; Strength of Evidence C: the recommendation is supported by indirect evidence (e.g., studies in normal human subjects, humans with other types of chronic wounds, animal models) and/or expert opinion. 


\begin{tabular}{l|l|l|l} 
Case Reports $\boldsymbol{h}$ & $\begin{array}{l}\text { Case Rep Dermatol 2010;2:120-124 } \\
\text { D01: } 10.1159 / 000317527\end{array}$ & Published online: July 2, 2010 & $\begin{array}{l}\text { O 2010 S. Karger AG, Basel } \\
\text { ISSN 1662-6567 } \\
\text { www.karger.com/cde }\end{array}$ \\
\hline
\end{tabular}

Fig. 1. Clinical appearance of the pressure ulcer. The DESIGN score was D4e2s4i2G3n1 = 16 .

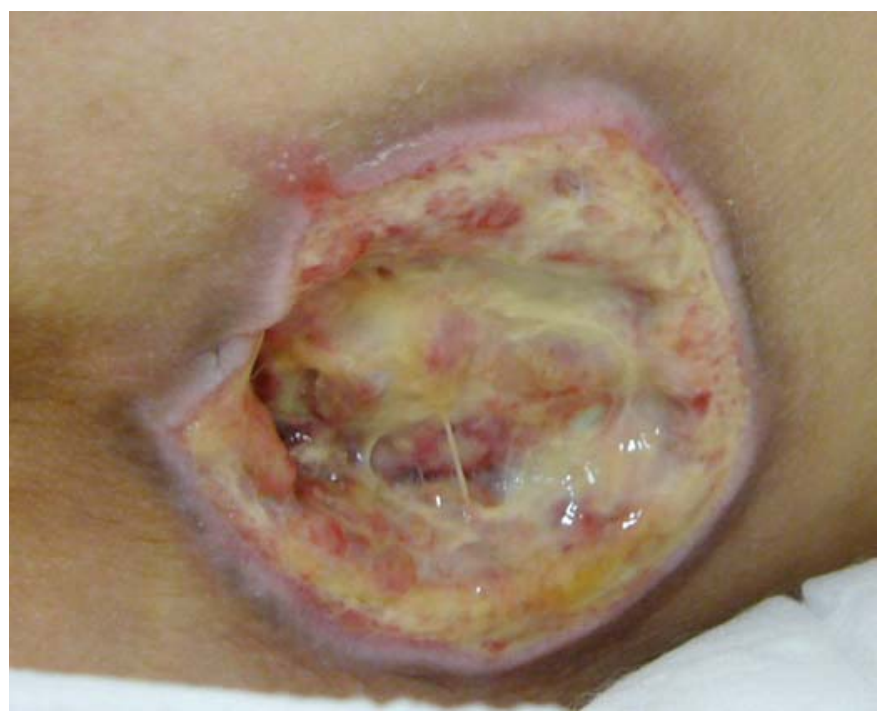

Fig. 2. Intake energy, topical treatment and DESIGN score in our case.

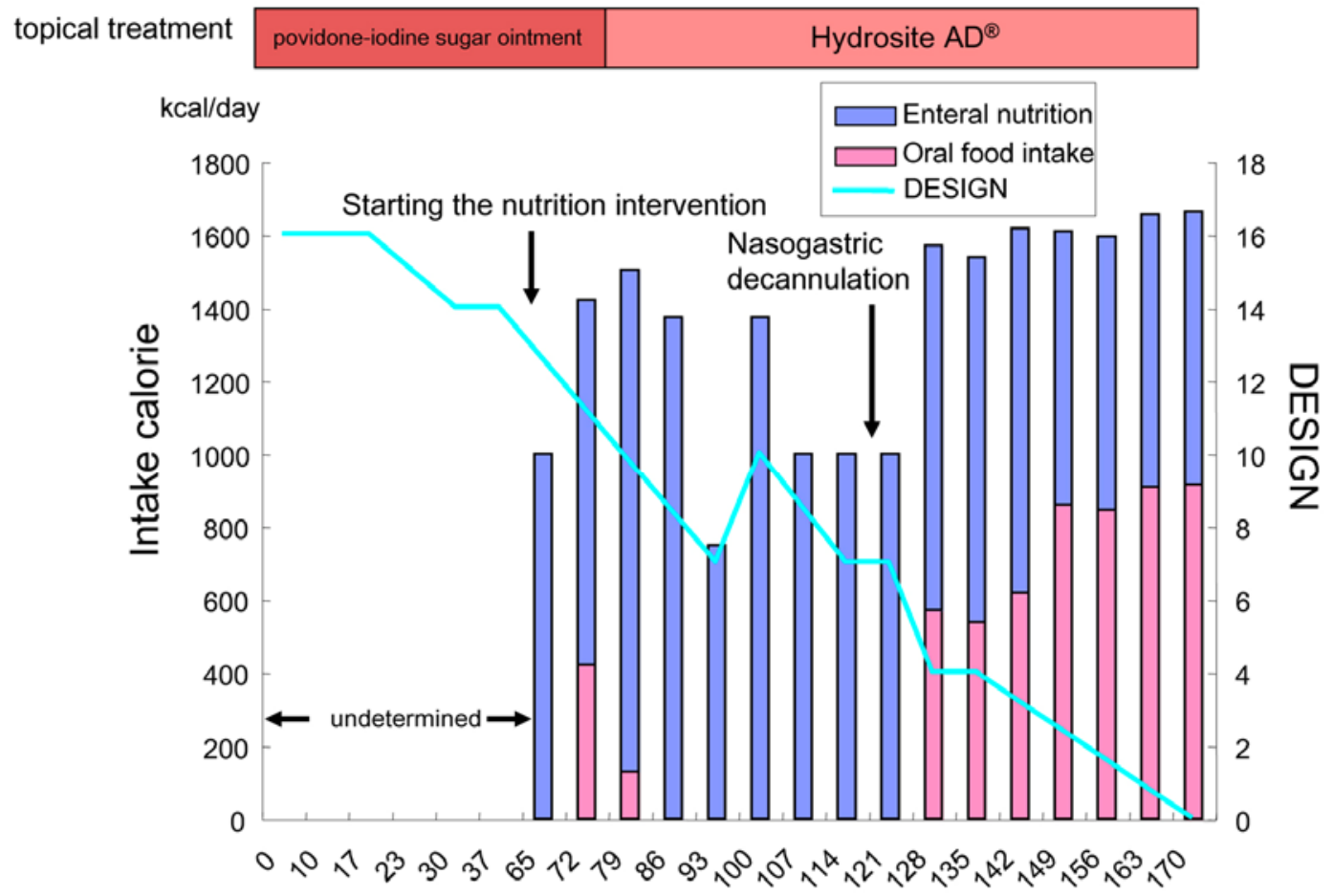

Days after consultation to the pressure ulcer advisory team 


\section{References}

1 Sanada H, Moriguchi T, Miyachi Y, et al: Reliability and validity of DESIGN, a tool that classifies pressure ulcer severity and monitors healing. J Wound Care 2004;13:13-18.

2 Japan Society of Pressure Ulcers. Guideline for Prevention and Management of Pressure Ulcers, ed. 1. Tokyo, Japan, Shorinsha, 2009.

-3 Inui S, Harada T, Nakajima T, et al: Two cases of pressure ulcer healing after liver transplantation in cirrhosis patients. J Dermatol 2007;34:400-402.

-4 Inui S, Itami S: A case of fissure-like pressure ulcer on the coccygeal area successfully treated with changing of wound dressing. Open Dermatol J 2008;2:93-94.

5 Stratton RJ, Ek AC, Engfer M, et al: Enteral nutritional support in prevention and treatment of pressure ulcers: a systematic review and meta-analysis. Ageing Res Rev 2005;4:422-450.

6 Oka R, Nakagawa Y, Shoji T, et al: Usefulness of a nutrition assessment system for parenteral/enteral nutrition therapy. Yakugaku Zasshi 2006;126:1351-1356.

7 European Pressure Ulcer Advisory Panel and National Pressure Ulcer Advisory Panel: Treatment of Pressure Ulcers: Quick Reference Guide. Washington DC, National Pressure Ulcer Advisory Panel, 2009. 